\title{
A Boy without Growth Hormone is Growing Normally
}

Mari Murashita, Kenji Fujieda, Toshihiro Tajima, Jun Nakae, Mikiko Kato and Nozomi Shinohara Department of Pediatrics, Hokkaido University School of Medicine, Hokkaido, Japan

\begin{abstract}
This is a 12 year and 5 month old prepubertal boy, who was followed from the neonatal period because of tertiary hypothyroidism. Endocrinological examinations were performed on three occasions. All the data revealed growth hormone (GH) deficiency and hypothyroidism. GH responses to insulin, arginine and GH-releasing factor (GRF), and the nocturnal GH secretion test, were low and sometimes undetectable. In addition, the serum insulin-like growth factor I (IGF-I) values were always low. Thyroid-stimulating hormone (TSH) responses to the TSH-releasing hormone (TRH) provocation test showed a tertiary hypothyroidism pattern. The values of luteinizing hormone (LH), follicle stimulating hormone (FSH), and testosterone were in the pre-pubertal stage and prolactin was in the normal range. Magnetic resonance (MR) imaging showed a small pituitary with stalk interruption, in spite of normal delivery.

With the use of levothyroxine, growth has been maintained in the range between -1 standard deviation (SD) and -2 SD. In this case GH and IGF-I are not indispensable for maintaining physical growth, and the abnormal pituitary imaging is not caused by perinatal insult. Further detailed investigations, including a search for some growth-promoting bioactivity other than GH, are needed to elucidate the mechanism of this patient's growth.
\end{abstract}

Key words: growth hormone deficiency, normal growth

\section{Introduction}

Growth without growth hormone $(\mathrm{GH})$ is difficult to reconcile with our present understanding of the role of $\mathrm{GH}$ in promoting postnatal growth. Several children with craniopharyngioma have been reported to show normal or excessive growth after surgical

Received: February 22, 1995

Accepted: October 25, 1995

Correspondence: Dr.Kenji Fujieda. Department of Pediatrics, Hokkaido

University School of Medicine, Kita 15-jyo, Nishi 7-chome, Kita-ku,

Sapporo-shi, Hokkaido 060 Japan removal of the tumor and subsequent documentation of GH deficiency (1-5). The growth of these patients has been attributed to hyperinsulinism secondary to obesity induced by hypothalamic damage (3). In another child lacking GH, normal growth was attributed to a putative growth factor that was not detected with a GH radioreceptor assay (6). Herein we report another such case in which a boy initially presented with tertiary hypothyroidism and GH deficiency, documented by endocrinological examination and imaging analysis. Treated with levothyroxine only, he is growing well despite 
continued absence of $\mathrm{GH}$.

\section{Case Report}

\section{1)Clinical course}

A boy, now $12 \frac{1}{2}$ years old, was born after full-term gestation with normal delivery, and was found to have low thyroxine by neonatal mass-screening. At that time, the levels of thyroxine ( $\left.\mathrm{T}_{4}\right)$ and thyroid-stimulating hormone (TSH) were low, indicating secondary or tertiary hypothyroidism. However, in the absence of clinical symptons and with low-normal levels of

\section{Cross-sectional Growth Chart for Boys (0-18 years)}

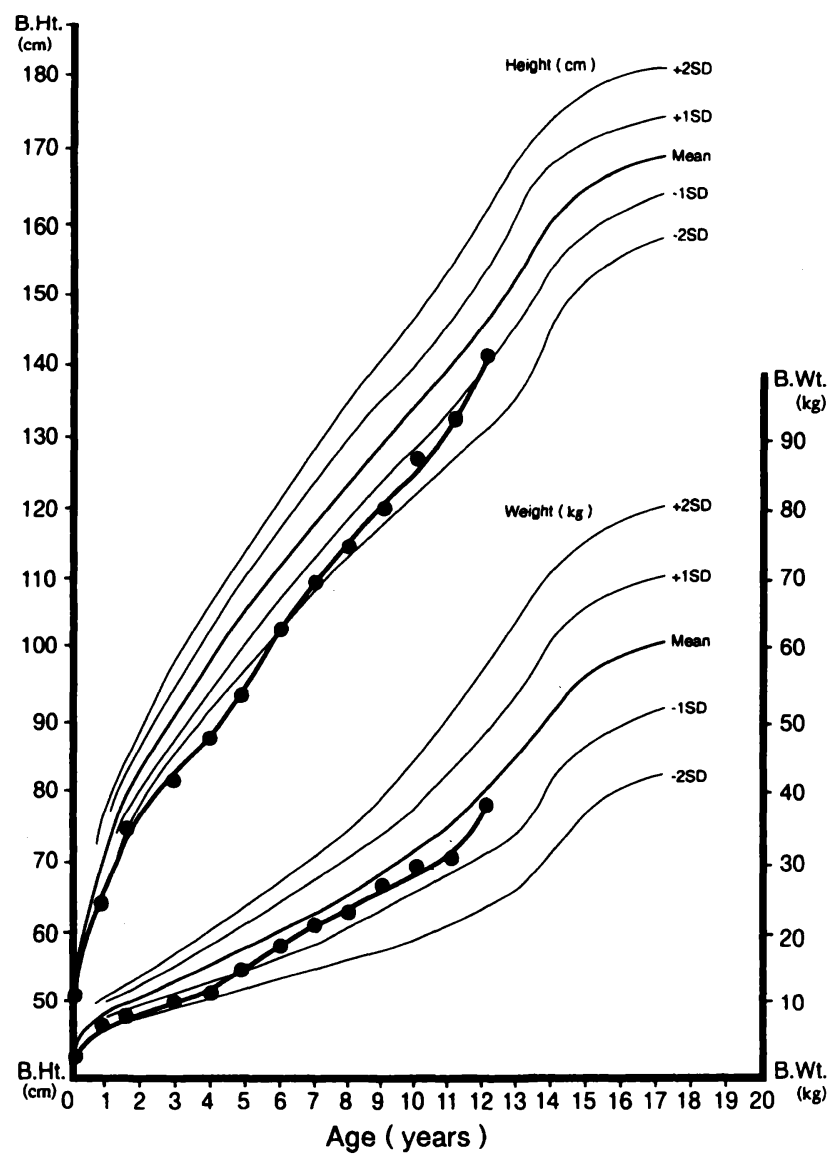

Fig. 1 Growth curve triiodothyronine ( $\mathrm{T}_{3}$ ) and $\mathrm{T}_{4}$, levothyroxine therapy was not started until the age of 20 months. At the age of 4.3 years, the levothyroxine was interrupted, because of a low-normal response to the TSH-releasing hormone (TRH) provocation test. Endocrinological examinations were performed on three occasions at the ages of $5.7,8.7$ and 12.0 years. GH deficiency was diagnosed first at 5.7 years. He has continued to grow, in spite of no secretion of $\mathrm{GH}$ and low insulin-like growth factor I (IGF-I). He was followed without levothyroxine therapy. The second and third examinations showed similar results. Levothyroxine was prescribed again at 8.7 years after the 2nd examination, and he grew well without GH and with low IGF-I (Fig. 1). At present he is being treated with levothyroxine only, although he has tertiary hypothyroidism and GH deficiency.

\section{2)Growth pattern}

The patient grew on the line of -2.1 standard deviation (SD) until 5.7 years of age when the diagnosis of hypothyroidism and GH deficiency was established. At 8.7 years, he had reached $120.4 \mathrm{~cm}$ in height (-1.5 SD) and 24.7 $\mathrm{kg}$ in weight. At 12.0 years, his height was 139.2

Table 1 Bone age and basal hormone data

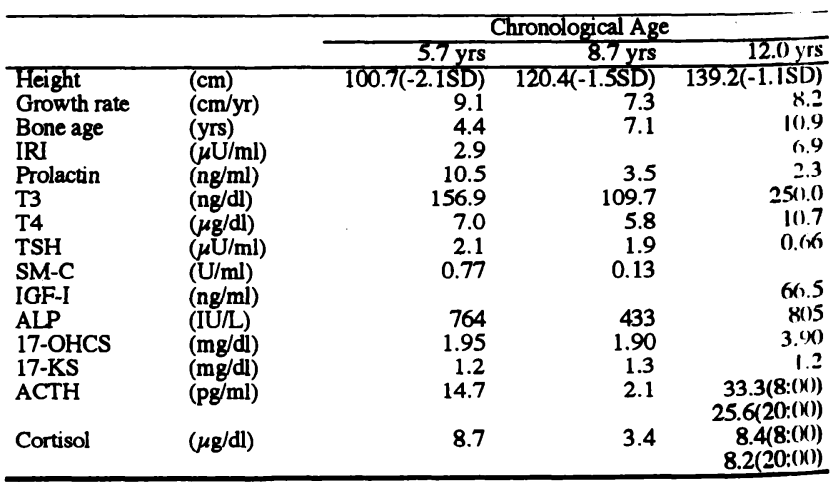


$\mathrm{cm}(-1.1 \mathrm{SD})$ and his growth rate was $8.2 \mathrm{~cm} /$ year (Fig. 1, Table 1). His secondary sexual characteristics were at Tanner stage I and testicular volume was $1.8 \mathrm{~mL}$. The facial appearance was similar to that seen in GH deficiency, with a prominent forehead, and an underdeveloped mid-face with a small nose and depressed nasal bridge. He had no thyromegaly, eunchoidism or other anomaly. Bone ages were 4.4, 7.1 and 10.9 years at the chronological ages of 5.7, 8.7 and 12.0 years, the bone age being thus constantly retarded.

\section{3)Endocrinological examination}

Hypothalamic-pituitary function was evaluated on three occasions, as mentioned above. The GH response to the insulin tolerance test was below the sensitivity limit on the first occasion; the peak $\mathrm{GH}$ value was $1.1 \mathrm{ng} / \mathrm{mL}$ on the second and $0.55 \mathrm{ng} / \mathrm{mL}$ on the third, both of which are quite low (Fig. 2-a). GH responses to arginine (Fig. 2-b) and GH-releasing factor (GRF)(Fig. 2-c) were always low. Physiological GH secretion was examined during the night (21:00-01:00) by collecting a blood sample every 20 minutes. The peak value of basal GH secretion was $0.5 \mathrm{ng} / \mathrm{mL}$, which was also low (Fig. 2-d). Plasma IGF-I levels were always low, with values of $0.13-0.77 \mathrm{U} / \mathrm{mL}$ and $66.5 \mathrm{ng} / \mathrm{mL}$ (Table 1). On TRH testing, serum TSH showed a low normal response at the first test and a delayed and sustained elevation of serum TSH at the second, suggesting tertiary hypothyroidism. At 12.0 years of age TSH response was not detectable, because he was on levothyroxine replacement (Fig. 3-a). The TRH response to prolactin was low to normal (Fig. 3-b). The results of serum luteinizing hormone $(\mathrm{LH})$ and follie stimulating hormone (FSH) responses to
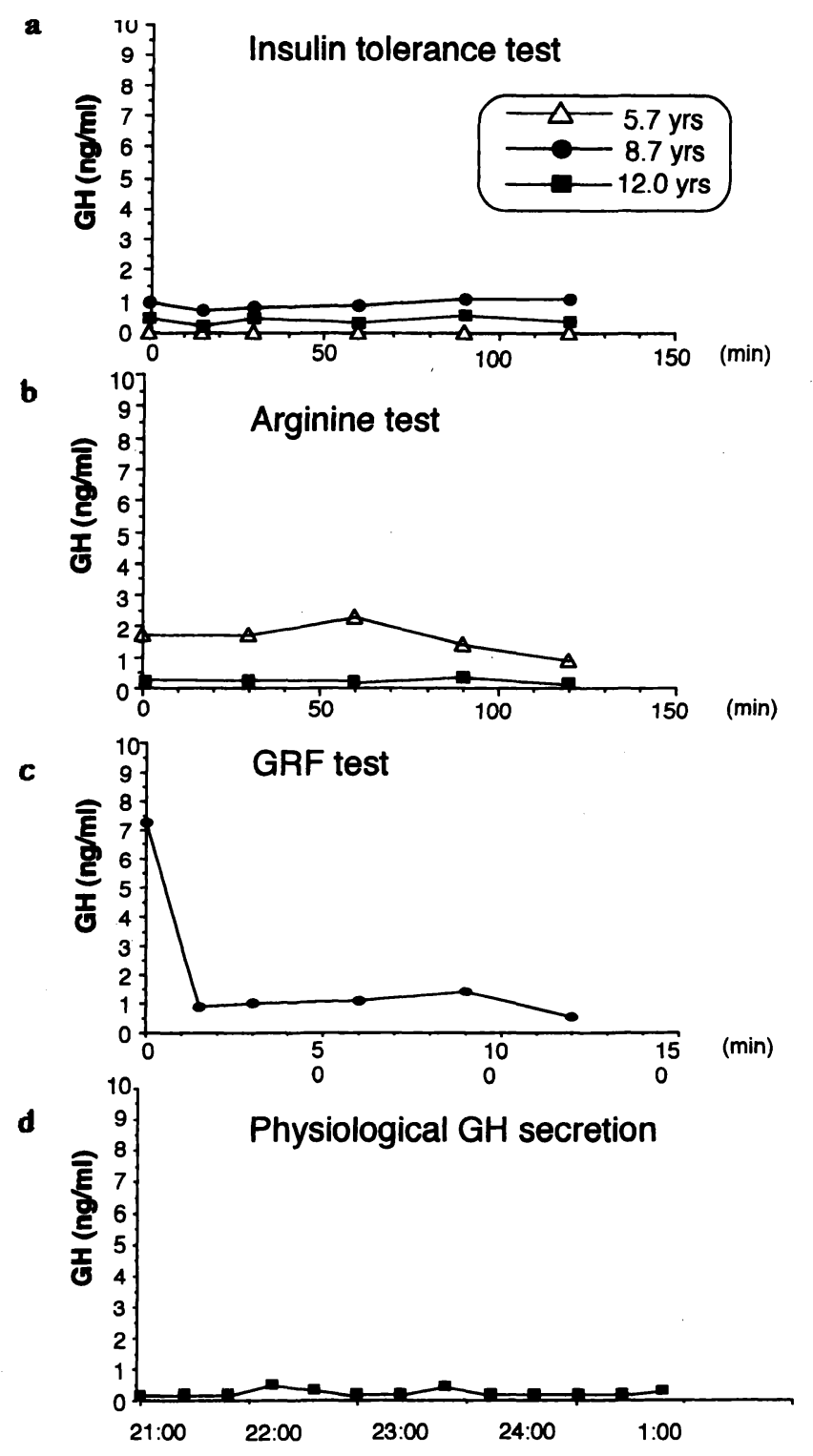

Fig. 2 Growth hormone responses to insulin, arginine and GRF test, and basal nocturnal GH secretion levels.

the LH-RH test were at the prepubertal stage in all 3 series of tests. The testosterone value of the human chorionic gonadotropine (hCG) test was low. The response of immuno reactive insuline (IRI) to the arginine tolerance test was not considered to be excessive. The values of urine 17-hydroxycorticosteroids (17-OHCS) and 17- 


\section{Murashita et al.}
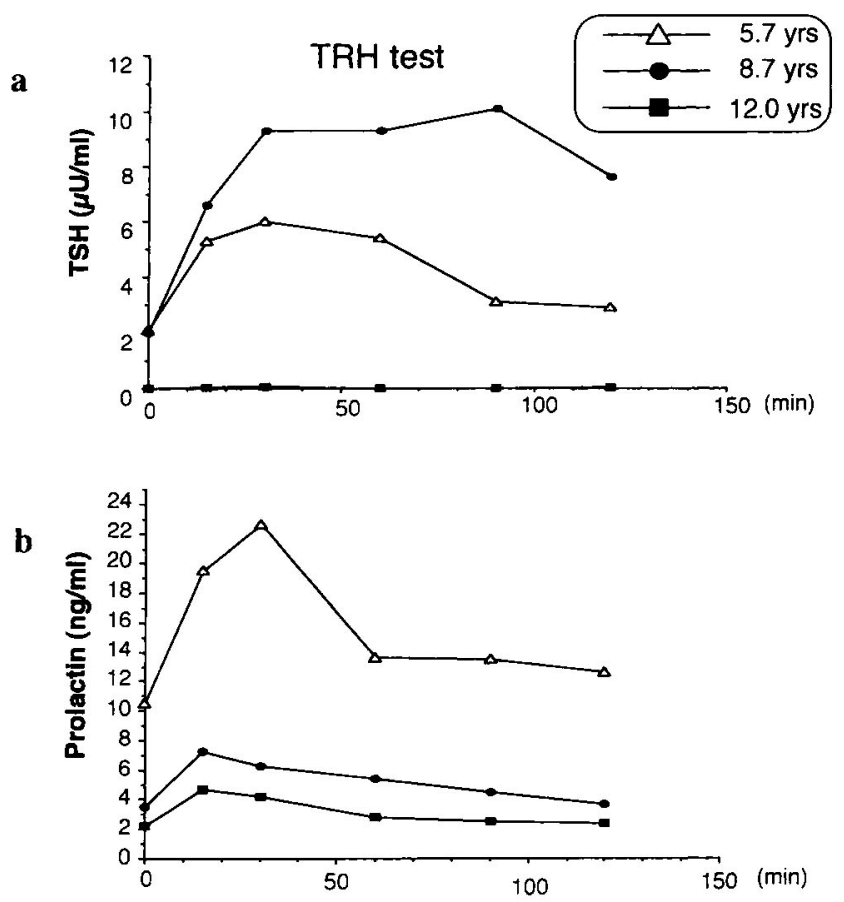

Fig. 3 TSH and Prolactin responses to TRH test.

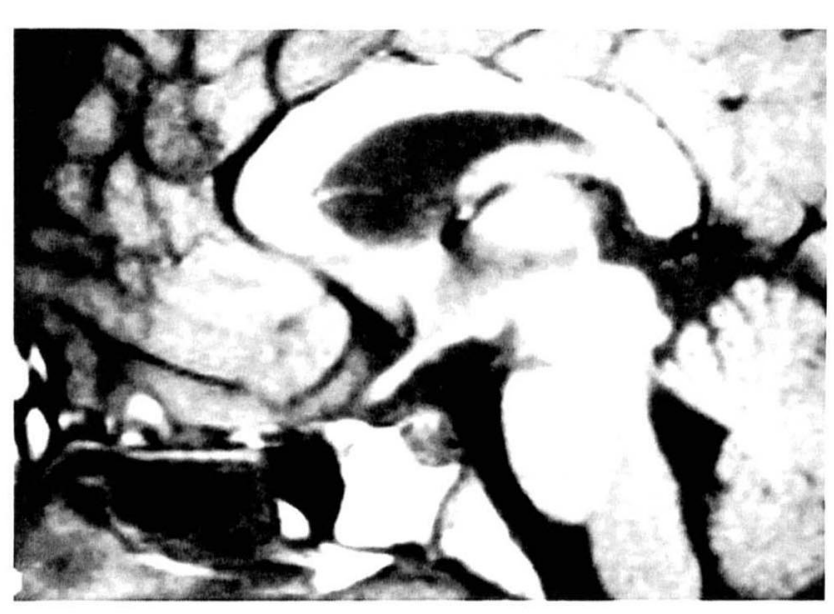

Fig. 4 Brain MR imaging.

ketosteroids (17-KS) were within the normal range. The basal adrenocorticotropic hormone (ACTH) and cortisol values were normal in spite of absence of diurnal rhythm. In addition, the responses of ACTH and cortisol to the insulin tolerance test were normal.

Brain MR imaging showed a small pituitary with stalk interruption (Fig. 4).

\section{Discussion}

GH is considered to be essential to linear growth. All children who have GH deficiency are expected to show impaired growth. In this report we present a boy who was diagnosed as hypothyroidism and $\mathrm{GH}$ deficiency by the results of endocrinological examination, but grew normally in spite of very low or undetectable secretion of GH and IGF-I.

The GH responses of this patient to insulin, arginine and the GRF test were quite low, and basal nocturnal GH secretion was also low. In addition to this low $\mathrm{GH}$ secretion, the level of IGF-I was always low, indicating that very little of the common growth factors was present in the serum. The TSH response to the TRH test showed a tertiary hypothyroidism pattern, and the prolactin response to $\mathrm{TRH}$ was low to normal. The response of IRI in arginine tolerance test (ATT) did not show hyperinsulinemii. The response of $\mathrm{LH}$ and FSH to the LH-RH test and of testosterone to the hCG test showed a hypogonadotropic hypogonadism pattern or prepubertal response. Adrenal function was normal.

These results suggest that in this boy at least three kinds of hormones are deficient, including GH, thyroid hormone and possibly gonadal hormones. The MR imaging, showing stalk interruption, may suggest a reason for these deficiencies. It is well known that traumatic breech delivery with perinatal hypothalamic damage is likely to be a cause of stalk interruption (7). Interestingly, however, in the 


\section{Growth without Growth Hormone}

present case, the pituitary stalk interruption occurred even though delivery was quite normal. The MR image and the panhypopituitarism may not be significantly related to perinatal injury. Although the significance of an absent, elongated, or atrophic pituitary stalk remains unknown, it may be a developmental defect or a lesion secondary to vascular or traumatic damage. It is important to perform MR examination in such children to obtain anatomical information, even after a normal delivery.

Although in the present patient MR imaging showed stalk interruption and endocrinological examination revealed panhypopituitarism, he needed treatment with only levothyroxine for his growth. The other complex hypopituitarism, GH/prolactin(PRL)/TSH deficiency, established as a new clinical entity caused by the pituitary-specific transcription factor (Pit-1/GHF-1) (Pit-1) gene abnormality, results in severe growth failure. This patient, however, grew normally with levothyroxine alone.

The mechanisms of his growth are hard to explain. GH and IGF-I were measured by radioimmunoassay (RIA), a method which is widely accepted. However, it is possible that since this assay measures immunological activity, there could have been a growth hormone with a biological activity hardly detectable by $\operatorname{RIA}(8,9)$. Another possible reason is that the secretion of a very low amount of GH or IGF-I may suffice to promote linear growth. Bucher et al. reported that post-operative patients with craniopharyngioma show excessive growth velocity due to hyperinsulinism secondary to hyperphagia and obesity, or to prolactin hypersecretion that might be responsible for IGF-I production (3). However, in the present case, there was no obesity and the baselines of insulin and prolactin were not high. The growth-promoting factor did not appear to be human GH or IGF-I. Bristrtzer et al. presented data of GH radio-receptor assay (RRA)/RIA ratio, corresponding to the ratio of bioactivity to immunoreactivity of the circulating $\mathrm{GH}$, in four $\mathrm{GH}$ deficiency patients, and showed that their GH RRA/RIA ratio exceeded the range of the controls. The unknown hormone, which could not be detected with standard GH RRA but is capable of binding to the GH receptors on IM-9 cells, might exist, and this unknown hormone mimics the biological activity of GH (10). Other groups have reported that some unknown factor that stimulates the colony formation of human erythroid progenitor cells (BFU-E) in the serum of acromegalic patients is responsible for the excessive growth (11). However, the growth factor found in patients with acromegaly dose not seem to be epidermal growth factor, nerve growth factor, fibroblast growth factor or platelet-derived growth factor since these have no activity in the BFU-E bioassay under these conditions. A similar report by Geffner et al. suggests that the patient's growth was independent of GH and IGF-I (6).

The mechanisms of the present patient's growth remain unclear. It is possible that he might have unknown growth factors, which have the similar action to $\mathrm{GH}$, but could not be detected by RIA. Further detailed investigations, including a search for bioactivity, are needed to elucidate these mechanisms. In addition, further careful follow-up is required, since his gonadal hormone levels are still prepubertal and his growth velocity may decrease after puberty. 


\section{Murashita et al.}

\section{References}

1. Thomsett MJ, Conte FA, Kaplan SL, Grumbach MM. Endocrine and neurologic outcome in childhood craniopharyngioma. Review of effect of treatment in 42 patients. J Pediatr 1980; 87: 728-35.

2. Lyen KR, Grant DB. Endocrine function morbidity and mortality after surgery for craniopharyngioma. Arch Dis Child 1982; 57: 837-41.

3. Bucher H, Zapf J, Torresani T, Prader A, Froesch ER, Illig R. Insulin-like growth factor I and II, prolactin and insulin in $\mathbf{1 9}$ growth hormone-deficient children with excessive, normal, or decreased longitudinal growth after operation for craniopharyngioma. N Engl J Med 1983; 309: 1142-6.

4. Stahnke N, Grubel G, Lagenstain I, Willim RP. Long-term follow-up of children with craniopharyngioma. Eur J Pediatr 1984; 142: 179-85.

5. Shinohara N, Fujieda K, Matuura N, Okuno A, Hosoda A, Kato M. Maintaining normal growth despite the presense of GH deficiency and low IGF-I value after operation of craniopharyngioma: Report of a case. Proceeding of "The 4th meeting of the reseach society for growth disturbance in children".
JEFF Corporation 1991; 77-83. (in Japanese)

6. Geffner ME, Bersch G, Kaplan SA, Lippe $\mathrm{BM}$, Herle AV, Elders MJ, et al. Growth without growth hormone: Evidence for a potent circulating human growth factor. Lancet 1986; 1: 343-7.

7. Fujisawa I, Kikuchi $K$, Nishimura $K$, Togashi K, Itoh K, Noma S, et al. Transection of the pituitary stalk: development of an ectopic posterior lobe assessed with MR imaging. Radiology 1987; 165: 487-9.

8. Francis MJO, Hill DJ. Prolactin-stimulated production of somatomedin by rat liver. Nature 1975; 255: 167-8.

9. Finkelstein JW, Kream J, Ludan A, Hellman L. Sulfation factor (Somatomedin): An explanation for continued growth in the absence of immunoassayable growth hormone in patients with hypothalamic tumors. J Clin Endocrinol Metab 1972; 35: 13-7.

10. Bistritzer T, Chalew SA, Lovchik JG, Kowarski AA. Growth without growth hormone: The "invisible" GH syndrome. Lancet 1988; 1: 321-3.

11. Aschcraft MW, Hartzband PI, Van Herle AJ, Bersch N, Golde DW. A unique growth factor in patients with acromegaloidism. $\mathrm{J}$ Clin Endocrinol Metab 1983; 57: 272-6. 